\title{
Are masters athletic performances predictive of human aging in men and women?
}

\author{
Jonathon W. Senefeld* and Sandra K. Hunter \\ Program in Exercise Science, Department of Physical Therapy, Marquette University, P.O. Box 1881, 53201-1881 Milwaukee, \\ WI, USA
}

Received 27 March 2019, Accepted 29 May 2019

\begin{abstract}
Human aging particularly after 70 years, is associated with declines in physical function and athletic performance, that are accelerated in part by age-associated declines in physical activity and exercise training. Because elite athletes maintain high levels of physical activity across the lifespan, older athletes (Masters) may present as a proxy for healthy human aging. Although longitudinal studies are most informative about human aging, there are substantial practical challenges to conducting longitudinally designed research. Masters athletic records and comparisons of performance across age groups can serve as a practical and unique probe to predict the trajectory of human function throughout the lifespan. While useful, the cross-sectional comparison of elite athletic performance across different age groups, however, has inherent limitations in predicting healthy human aging, particularly among women. This review presents evidence that (1) there is a progressive age-related decline in world class performances in freestyle swim swimming, marathon, and triathlon, that accelerates into very old age ( $\sim 70$ years $)$, and $(2)$ lower participation rates of women relative to men results in an overestimation of the age-related decline in athletic performance particularly in very old women. Thus, while useful, there are some limitations to predicting biological aging among women using current Masters Athletic performances.
\end{abstract}

Keywords: sex differences, swimming, marathon, triathlon

Résumé - Les performances des athlètes masters sont-elles prédictives du vieillissement humain chez les hommes et les femmes? Le vieillissement humain, particulièrement après 70 ans, est associé à un déclin des fonctions physiques et des performances athlétiques, qui est accéléré en partie par le déclin du niveau d'activité physique et d'entraînement avec l'âge. Étant donné que les athlètes élites maintiennent un haut niveau d'activité physique tout au long de leur vie, les athlètes âgés (Masters ou Vétérans) pourraient représenter un modèle du vieillissement humain en bonne santé. Bien que les études longitudinales sont les plus représentatives du vieillissement humain, elles comportent d'importants défis pratiques. Les records sportifs des Masters et la comparaison des performances en fonction du groupe d'âge peuvent servir de modèle unique et pratique pour prédire la trajectoire du fonctionnement humain tout au long de la vie. Bien qu'utile, la comparaison transversale des performances sportives d'élite de différents groupes d'âge présente cependant des limites inhérentes à la prévision d'un vieillissement en bonne santé, en particulier chez les femmes. Cette revue présente des preuves (1) qu'il y a un déclin progressif des performances de niveau mondial avec l'âge en natation nage libre, marathon et triathlon, qui s'accélère chez les personnes très âgées, et (2) le plus faible taux de participation des femmes comparé aux hommes entraîne une surestimation du déclin des performances athlétiques avec l'âge, particulièrement chez les femmes très âgées. Ainsi, bien qu'utile, il y a des limites à prédire le vieillissement biologique des femmes en utilisant les performances athlétiques actuelles des Masters.

Mots clés : différences entre les sexes, natation, marathon, triathlon

\footnotetext{
*Corresponding author: jwsenefeld@gmail.com
} 


\section{Introduction}

Human aging is a complex phenotype and from even as early as $\sim 30$ years old is characterized by a gradual decline in the function of cells, organs and tissues throughout many systems in the human body (Belsky et al., 2015; Lara et al., 2015). This decline in function is accelerated in part by inactivity and results in a continuum of physical impairments with advanced age for example, in the neuromuscular, respiratory and cardiovascular systems (Hunter, Pereira, \& Keenan, 2016), which are important for athletic performance and activities of daily living. Furthermore, there is a major demographic shift toward aging societies in many countries, for example, from 2010 to 2050 the number of adults over age 65 should be more than double in the United States (Prevention, 2013). Because of this demographic shift and the large economic burden to support older adults, a primary global societal goal is to promote healthy human aging (Lara et al., 2015; Vaupel, 2010).

Age-related declines in activity levels and exercise training can accelerate the reductions in physical function and performance in older adults (DiPietro, 2001). Because elite athletes maintain high levels of physical activity, older elite athletes (Masters athletes) may serve as a proxy for the best of healthy human aging. Cardiorespiratory fitness, measured as maximal or peak oxygen consumption $\left(\mathrm{VO}_{2 \max }\right)$ during intense exercise such as running or bicycling, for example, is one of the best indices of healthy aging (Lazarus, Lord, \& Harridge, 2019) and is an important prognostic factor of mortality (Myers et al., 2002). The reduction in $\mathrm{VO}_{2 \max }$ across the lifespan is reported to be $\sim 9-10 \%$ per decade for men (Heath, Hagberg, Ehsani, \& Holloszy, 1981) and women (Fitzgerald, Tanaka, Tran, \& Seals, 1997), indicating a $\sim 1 \%$ decline each year. In elite athletic populations, $\mathrm{VO}_{2 \max }$ values can be very high relative to recreationally active and sedentary adults of similar age (Trappe et al., 2013). Despite high physical activity levels and limited comorbidities in elite older athletes, $\mathrm{VO}_{2 \max }$ values progressively decline with advanced age (Fitzgerald et al., 1997; Pimentel, Gentile, Tanaka, Seals, \& Gates, 2003; Trappe, Costill, Vukovich, Jones, \& Melham, 1996), primarily due to the steady reduction of maximal heart rate that is independent of activity levels (Tanaka \& Seals, 2008). Thus, it is possible that athletic populations could be used as a proxy for healthy human aging, with performance times serving as a useful tool to predict the trajectory of biological aging (Donato et al., 2003; Joyner, 1993; Lazarus \& Harridge, 2017; Tanaka \& Seals, 2003, 2008). The trajectory of the decline in elite athletic performance across the lifespan is largely independent of disease and the activity declines that accelerate the age-related reductions in physical function. This convenient cross-sectional comparison of elite athletic performance across different age groups, however, has inherent limitations in predicting healthy human aging in men and women, some of which are highlighted in this review.
Therefore, the purpose of this review is to evaluate the utility of world class athletic performances as a proxy to characterize the decline in physiological function that occurs with healthy aging. This review presents evidence that:

- there is a progressive age-related decline in world class performances of freestyle swimming, marathon running, and triathlon performance;

- there is a dearth of data for women possibly limiting the utility of using Masters athletic performances as an accurate proxy in predicting biological aging among women.

Following is a discussion of whether Masters athletic performance is a useful model for healthy aging.

\section{Who is a Masters athlete?}

The term 'Masters athlete' was originally coined by the sport of athletics (track and field) to denote athletes over the age of 35 years, and the first World Masters competition was held in 1975. Many sports now incorporate 'Masters athletes' in regular and elite competitions, although the minimum age cutoff varies significantly by sport (Ransdell, Vener, \& Huberty, 2009). For example, eligibility for Masters swimming begins at 18 years. For many sports, there has been a long-standing regular World and National competitions among Masters athletes with elite qualification standards and competitions delineated into many separate 5year competition brackets (e.g. 65-69 years). Results from these world class competitions are often archived in publicly-available databases, which provide a convenient testbed to evaluate the utility of elite athletic performance as a proxy for healthy human aging. For the purpose of this broader discussion of Masters athletes serving as a proxy for human biological aging, we will first summarize some of the notable age-related changes in physiology that affect performance and then highlight studies demonstrating the decline in performance of elite male and female athletes across age groups.

\section{Physiological and morphological changes with human aging}

Several age-related changes in the human body decrease motor performance even in the highly active Masters athletes. Skeletal muscle atrophies with advanced aging (i.e. sarcopenia) (Hunter et al., 2016) due to a loss of motor units and atrophy of all muscle fibers with a preferential loss of muscle expressing type 2 myosin heavy chain isoforms (Nilwik et al., 2013; Sundberg, Hunter, Trappe, Smith, \& Fitts, 2018). Even among world-class octogenarian masters athletes, there is a large loss in the number of motor units (i.e. the motor nerve and the fibers it innervates) and also a reduction in muscle fiber contractile velocity (Power, Allen et al., 2016; Power, Minozzo et al., 2016). Ultimately, maximal strength, speed and power producing capacity of limb muscles declines 

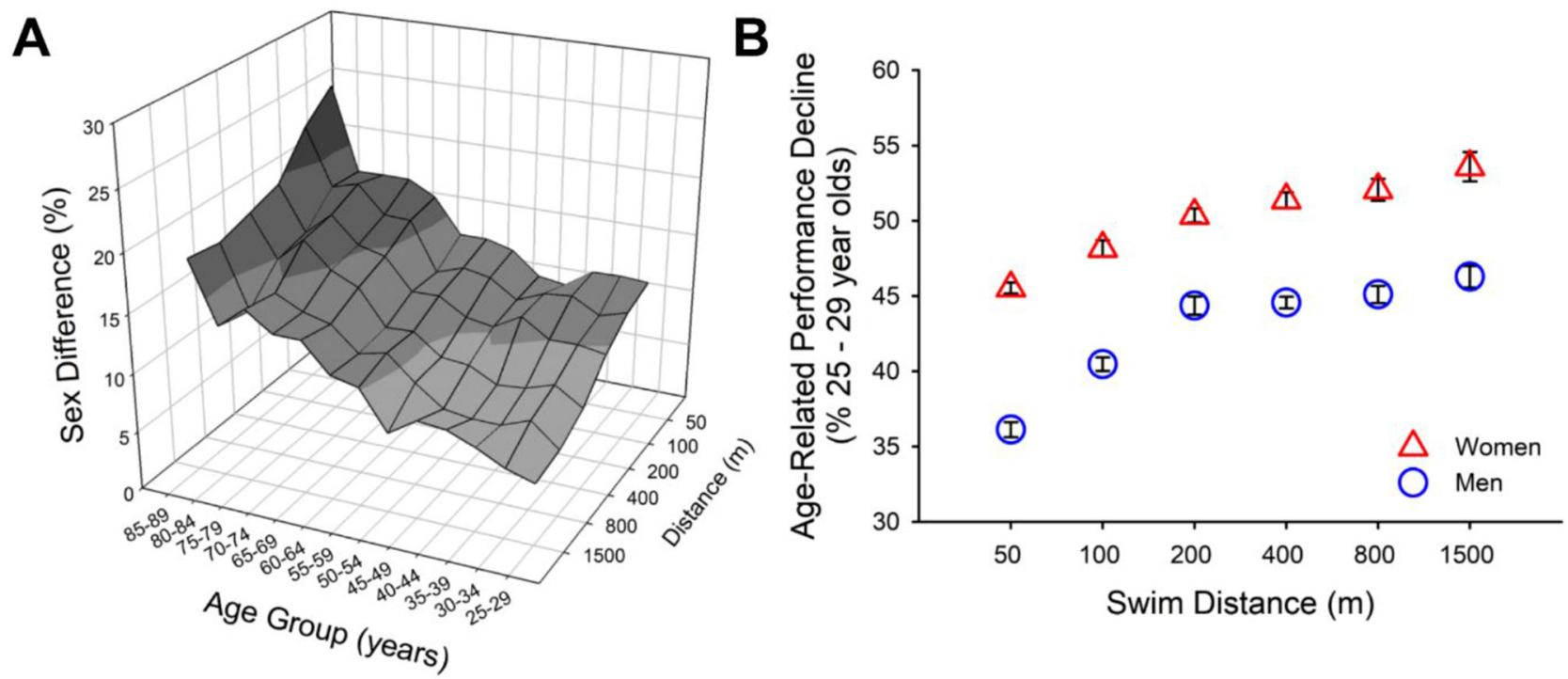

Fig. 1. World's fastest long-course freestyle swimming performances. (A) Average sex difference in swimming velocity (z-axis) across 5-year age groups 25 to 89 years (x-axis) and event distances 50 to $1500 \mathrm{~m}$ (y-axis). Greater sex differences were observed in older age groups and shorter race distances, with the largest sex difference for the $50 \mathrm{~m}$ in $85-89$ year age group. (B) Average age-related performance decline (performance of 85-89 age group relative to 25-29 year age group) for women (red triangle) and men (blue circle) across swim event distances 50 to $1500 \mathrm{~m}$. Age-related declines in performance were less for shorter (50 and $100 \mathrm{~m})$ compared with the longer event distances (200 m up to $1500 \mathrm{~m}$ ). Data were extracted from Senefeld and colleagues (Senefeld et al., 2016).

markedly with advanced aging (Hunter et al., 2016; Sundberg et al., 2018).

In addition to age-related changes in muscle mass and composition, age-related impairments in mitochondrial function (Hepple, 2014) and cardiovascular function result in a reduction in maximal oxygen consumption (i.e. $\mathrm{VO}_{2 \max }$ ) in older adults (Joyner, 1993; Joyner \& Coyle, 2008). Oxygen consumption is the product of cardiac output (heart rate $\times$ stroke volume) and the oxygen extracted from the skeletal muscle $\left(\mathrm{a}-\mathrm{vO}_{2}\right.$ difference). In elite master's athletes, the age-related reduction in maximal heart rate that occurs independent of activity level, is the primary cause of the steady decline in $\mathrm{VO}_{2 \max }$ with aging (Fitzgerald et al., 1997; Joyner \& Coyle, 2008). In endurance-trained adults, there are reported modest reductions $(\sim 10 \%)$ in stroke volume and a-v $\mathrm{O}_{2}$ difference (Tanaka \& Seals, 2008). Thus, even in the fittest and healthiest old adults, the age-related loss of skeletal muscle mass and $\mathrm{VO}_{2 \max }$ will reduce athletic performance.

Importantly, there are expected physiologic sex differences in physical function across all age groups. Women for example, on average have less muscle mass, greater body fat, lower hemoglobin concentrations and lower maximal cardiac output than men (Hunter, 2016a, 2016b; Joyner, 1993, 2017). These sex differences contribute to a $\sim 10 \%$ lower $\mathrm{VO}_{2 \max }$ in women than men and slower speeds of maximal exercise performance of $\sim 10-12 \%$ such as running (Hunter, 2016a, 2016b; Joyner, 1993, 2017). Following is a description of the trajectory of that decline in elite athletic performance of men and women across the age groups.

\section{Athletic performance in elite Masters athletes}

Many studies have compared world class and elite performances of young and Masters athletes even up to 100 years of age in various sports. These cross-sectional data sets show large age-related declines in performance including in swimming, marathon, and triathlon. For example, we accessed the world records of the top 10 alltime long course swimming times for men and women between 1986 and 2011 for four swimming strokes (freestyle, backstroke, butterfly and breaststroke) and for all race distances available (up to $1500 \mathrm{~m}$ for freestyle) (Senefeld, Joyner, Stevens, \& Hunter, 2016). Performance times were then converted into performance velocities. For the men's $1500 \mathrm{~m}$ freestyle (top 10 averaged), there was almost a threefold slowing in swimming velocity between the 25-29 year-old $\left(90.5 \mathrm{~m} \cdot \mathrm{s}^{-1}\right)$ and $85-89$ year old men $\left(34.2 \mathrm{~m} \cdot \mathrm{s}^{-1}\right.$; Fig. 1A). The magnitude of slowing in swimming performance from the youngest to oldest age group was similar for women $\left(85.7\right.$ vs. $\left.32.4 \mathrm{~m} \cdot \mathrm{s}^{-1}\right)$ compared with the men (Senefeld et al., 2016). This agerelated reduction in swimming performance occurred for both men and women for each swimming stroke and swimming distance, with the largest age-related differences in the longer distance event $(1500 \mathrm{~m})$ compared with the sprint distance swims (50 m; Fig. 1B). The greater age difference in performance for the $1500 \mathrm{~m}$ freestyle swim relative to the $50 \mathrm{~m}$ is likely due to the specific energetic demands of the events. World class performance times for the $1500 \mathrm{~m}$ swim are over 15 minutes for young men and 20 minutes for older men, whereas world class performance 
times of the $50 \mathrm{~m}$ swim are $\sim 22$ seconds for young men and $\sim 30$ seconds for older men. Maximal performance of the $1500 \mathrm{~m}$ swim will be limited by both aerobic capacity and muscular power and endurance which whereas the short $50 \mathrm{~m}$ sprint distance is likely to be limited more by muscular power with limited contribution of aerobic capacity (Tanaka \& Seals, 1997).

This above example featuring swimming is one of many studies that have compared world records, or elite athletic performance across age brackets up to 100 years of age. One of the commonalities in these studies is the nonlinear decline in performance of both men and women across the age groups, with the greatest reductions in performance after 60 years. Figure 2 summarizes data from world class performances in swimming, the marathon and triathlon, showing a common trajectory of reduction across age groups. Data are shown from Masters athletes from Olympic distance and Ironman distance World Championship triathlon (Lepers \& Maffiuletti, 2011), World masters top 10 all-time age-group records for long-course swimming and marathon running (Senefeld et al., 2016) that are plotted across the range of 5-year competition age brackets relative to the youngest age group (25-29 years). Using correlation modeling within three broad age categories (young, 25-44 years; middle-aged, 45-64 years; older adults, 65-99 years), the group data demonstrates a decline in athletic performance of $0.25 \% \cdot$ year $-{ }^{1}$ within the young, $0.88 \% \cdot$ year $^{-1}$ for middle-aged, and $1.2 \%$. year $^{-1}$ for older adults (Fig. 2A). However, the decline is not equitable for the men and women. While the net reduction in athletic performance from 25 to 89 years was $46.5 \%$, men had a lesser age-related reduction in performance $(42.8 \%$ ) compared with women (51.1\%) (Fig. 2B). Several observations can be made from these combined data sets. First, the rate of decline in performance across the age groups accelerated with age, with the steepest reductions between 65 and 89 years. Second, while the overall reduction in athletic performance was $\sim 7.2 \%$ per decade, the men demonstrated a slower rate of decline (6.6\% per decade) compared with the women $(7.7 \%$ per decade). This sex difference in Masters athletic performance was most apparent in the old age groups.

Overall, this reduction in world class athletic performance across the age groups equates to $\sim 0.7 \% \cdot$ year $^{-1}$ between 25 and 89 years (Fig. 2B). However, this rate is less than the age-related reduction in $\mathrm{VO}_{2 \max } \sim 1 \% \cdot$ year $^{-1}$ observed in cross-sectional studies for men and women (Fitzgerald et al., 1997; Heath et al., 1981; Pimentel et al., 2003). In contrast, a 22-year longitudinal study of elite male distance runners reported the age-related decline in $\mathrm{VO}_{2 \max }$ was considerably less for the men who maintained a high level of training $\left(0.6 \% \cdot\right.$ year $\left.-^{1}\right)$ than men who did not engage in regular physical activity for more than 5 years $\left(1.5 \% \cdot\right.$ year $\left.^{-1}\right)$ (Trappe et al., 1996). Thus, some cross-sectional data sets of physiological function such as $\mathrm{VO}_{2 \max }$ could be inflated because of lifestyle factors that change with advanced aging such as a reduction in training volume and intensity (Fitzgerald et al., 1997;

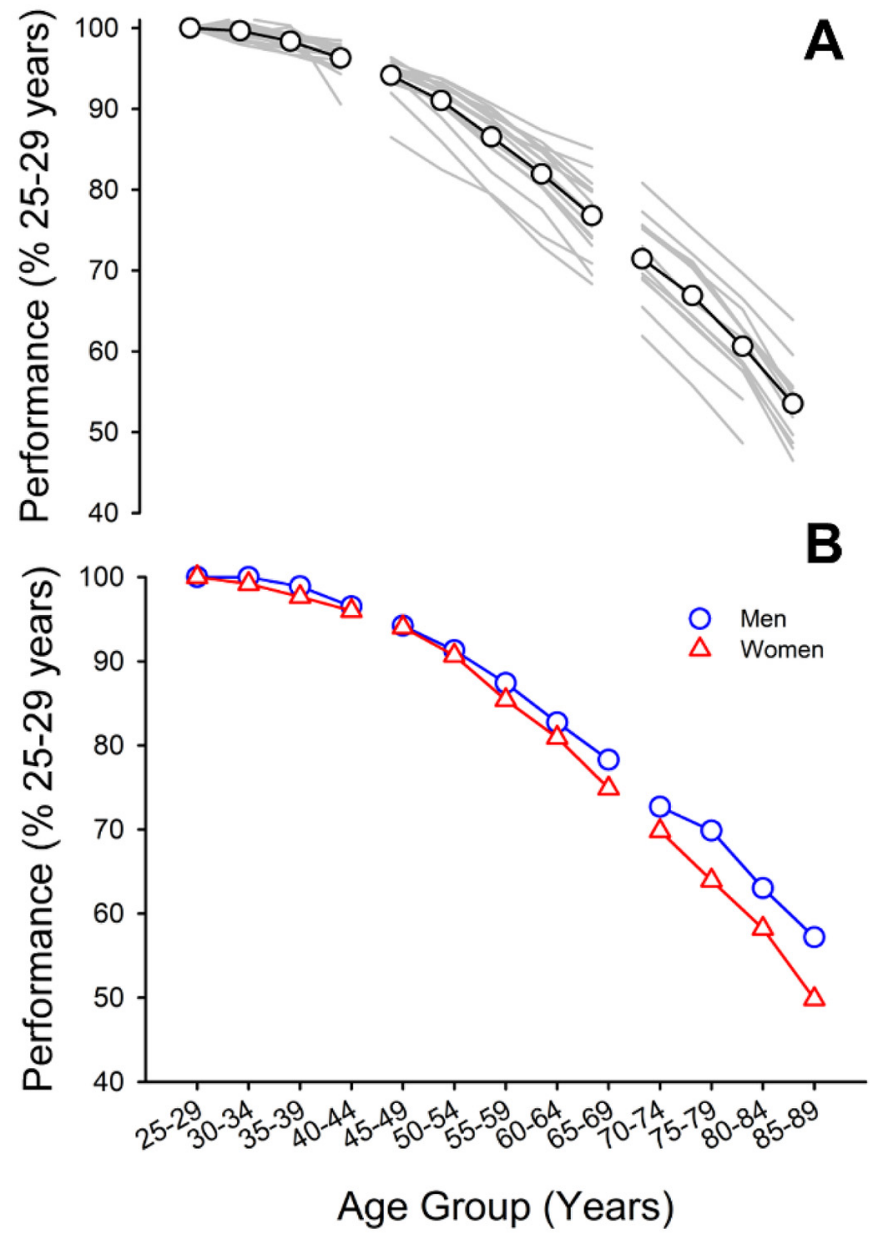

Fig. 2. Masters Athletes relative performance decline across the lifespan. (A) Performance, relative to the youngest age group, declined linearly across age group for young adults (25-44 years; $\left.r=-0.916, r^{2}=0.839, p<0.001 ; \mathrm{y}=-0.248 \mathrm{x}+101.68\right)$, middleaged adults (45-69years; $r=-0.993, r^{2}=0.986, \quad p<0.001$; $\mathrm{y}=-0.875 \mathrm{x}+99.22)$ and older adults (70-89 years; $\left.r=-0.991, r^{2}=0.982, p<0.001 ; \mathrm{y}=-1.202 \mathrm{x}+78.14\right)$ on average (open circles). Each grey line represents performance data from a single event including data for men from 2 years (2006, 2007) of World Championships for triathlons of Olympic and Ironman distance (Lepers, Sultana, Bernard, Hausswirth, \& Brisswalter, 2010), top 10 World performances for men and women from a 25-year period (1986-2011) for freestyle swimming of championship performance distances (50, 100, 200, 400, 800 and $1500 \mathrm{~m}$ ) (Senefeld et al., 2016), and top 10 performances of all time from road marathon racing (Senefeld et al., 2016) in 5-year age groups from 25 years up to 74 years for triathlon, 89 years for swimming and 84 years for marathon. (B) From the same datasets, the average relative performance declined linearly across age group with similar slope coefficients compared to the group data for men (blue circles) and women (red triangles) for young adults $(-0.231$ vs. -0.271 for men and women, respectively), middle-aged adults $(-0.809$ vs. -0.961 , respectively) and older adults ( -1.068 vs. -1.314 , respectively). Middle- and older-aged women had larger magnitude slope coefficients compared with the men, reflecting greater reductions in performance across the lifespan for women. Data were extracted from Senefeld and colleagues (Senefeld et al., 2016). 
Trappe et al., 1996). The similar reductions in elite athletic performance and $\mathrm{VO}_{2 \max }$ within longitudinal studies support the use of Masters athletic performance as a proxy for healthy human aging independent of the effects of reduced physical activity (Harridge \& Lazarus, 2017; Lazarus \& Harridge, 2017; Lazarus et al., 2019).

\section{Are elite Masters performances a proxy for human biological aging?}

There are, however, several potential limitations of using world class performance records of Masters athletes to predict the trajectory of human biological aging. These limitations include:

- differential participation between men and women in athletic performance events especially among older age groups;

- cross-sectional data as the primary source to predict human aging.

\subsection{Differential participation between sexes}

A near universal finding from studies of Masters athletes is the decline in performance across age groups is greater for women than men (Donato et al., 2003; Hunter \& Stevens, 2013; Hunter, Tevens, Magennis, Skelton, \& Fauth, 2011; Joyner, 1993; Lepers \& Maffiuletti, 2011; Senefeld et al., 2016; Tanaka \& Seals, 2003, 2008). This is illustrated in Figure 2. The greater reduction in women is counterintuitive because on average women live longer than men by about 5 years (Arias \& Xu, 2018). If we assume that within elite competition, there is minimal difference in motivation between the sexes, one conclusion could be that women experience a greater decline in physiological function as they age compared with men. However, studies report that the decline in physiological function with increased age is either less for women than men or similar between the sexes. For example, women have less relative age-related declines in $\mathrm{VO}_{2 \max }$ (Weiss, Spina, Holloszy, \& Ehsani, 2006) or the age-related declines are similar in magnitude between the sexes (Fitzgerald et al., 1997; Pimentel et al., 2003). Thus, while prediction models of world class athletic performance across age groups clearly demonstrate a greater decline for women than men, these findings are not consistent with epidemiologic and physiologic data.

Perhaps, a more plausible cause of the greater age-related decline in performance of elite female athletes is a lower participation rate in athletic competition among older women relative to older men due to different competitive opportunities (Joyner, 1993). A lower number of participating women would result in a reduced talent pool among the women. Historically, women have been banned from many endurance athletic competitions. As an example, women were not allowed to compete in the Olympic marathon until the 1984 Olympic Games despite men competing in the Olympic marathon since 1896. When women were first permitted to run the marathon in the 1970s, the world record began to plummet in time as more women competed, and the talent pool and training experience began to approach greater equity between men and women (Hunter, Joyner, \& Jones, 2015). However, the lack of opportunity for women can have lasting consequences.

There is growing evidence to suggest there is a lack of depth in Masters athletic performance times even among elite athletes (Hunter \& Stevens, 2013; Senefeld et al., 2016). For example, the number of annual participants aged 50-70 years in the New York City marathon from 1980-2010 was negatively correlated with the mean finishing time of the top 10 men and women within that 20-year age group (Hunter \& Stevens, 2013; Senefeld \& Sundberg, 2017), such that a greater number of participants was associated with a lower mean finishing time (Fig. 3). Due to historical bans of women in athletic competitions (particularly the marathon), many of the older women were not exposed to the same competition and training opportunities as age-matched men. As such, this relationship between finishing times and the number of runners differed for the men and women. For men, the correlation between annual participants and finishing time was linear with a small slope coefficient $(-0.0013$ $\mathrm{min} \cdot$ participant $\left.^{-1}\right)$. This demonstrates that large fluctuations in the number of participating men did not greatly impact finishing time and suggests that the talent pool was sufficiently representative of the population at large. For example, 1000 additional male participants would result in a reduction of average finishing time by 1.3 minutes. For the women, however, the correlation was steep and curvilinear when there were less than 1500 participants (Fig. 3). Above 1500 women participants the relationship become linear and less steep although the slope coefficient was still modestly larger than the men $(-0.0062 \mathrm{~min}$. participant $^{-1}$ ). Taken together these results suggest there is a threshold in the number participants at which the group is representative of the best talent aged 50-70 years for men and women in the marathon. For this event, at least 1500 female participants were needed. Participation numbers below that would appear to overestimate the sex difference and the reduction in performance with increased age because the pool of runners that did not represent the best within the population. For men, there was no observed threshold of participants that substantially altered the relationship between participant numbers and finishing times. Thus, we speculate that the best men were participating, and the talent pool for this event was considerably deeper than women possibly due to selfselection even prior to the race. It is conceivable that women remain influenced by institutional, economic and societal factors that can limit the potential pool of athletes (Angus, 2019; Hunter et al., 2015) and thus limit use of elite athletic performances to fully understand the trajectory of human aging among women.

\subsection{Cross-sectional data}

Although longitudinal studies have the potential to be the most informative research on human aging, there are 


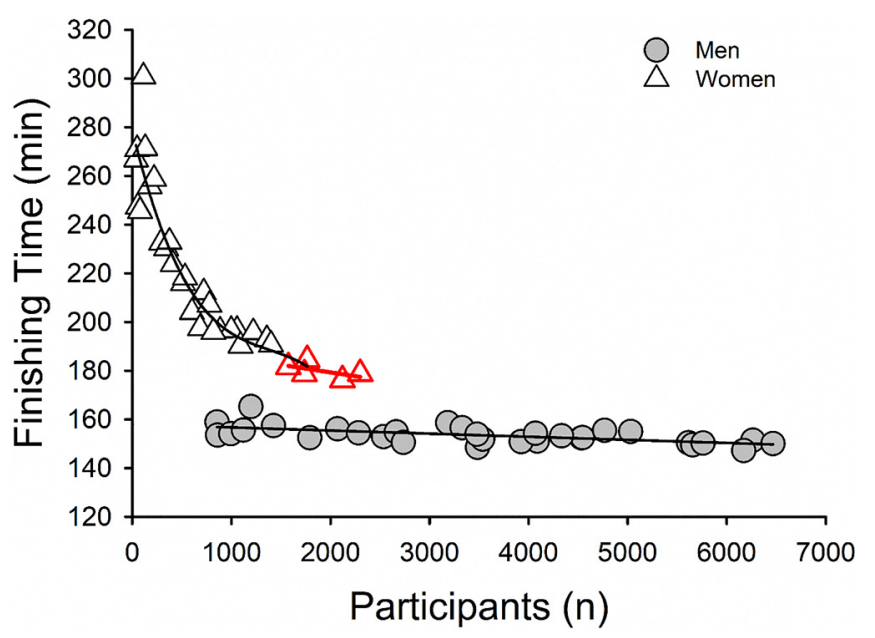

Fig. 3. Annual participation trends for the New York City Marathon between 1980-2010 for older (50-70 years) men and women. The number of participants was correlated with finishing time for men (grey circles; $r=-0.617, r^{2}=0.381, p<0.001$; $\mathrm{y}=-0.0013 \mathrm{x}+157.98$ ) and women (unfilled triangles; $r=0.948$, $\left.r^{2}=0.899, p<0.001\right)$. For the men, the correlation was linear across the range of annual participation numbers $(n=855-$ $6467)$; however, the association for the women was cubic with an approximate horizontal asymptote at $\sim 180$ minutes and which corresponds to approximately 1500 participants. For women, the correlation between participants and women was linear when participation was over 1500 participants (red triangles; $\left.r=-0.592, r^{2}=0.350, p<0.001 ; \mathrm{y}=-0.0062 \mathrm{x}+191.80\right)$. Data were extracted from Hunter and Stevens (2013).

substantial financial and logistical barriers to their execution (Lazarus \& Harridge, 2017). Consequently, data from longitudinal research is insufficiently available in many areas of human aging (particularly physical function), thus, there is a reliance on cross-sectional data (Kuh, Karunananthan, Bergman, \& Cooper, 2014). There are many physiological reductions in the neural, muscular and cardiovascular systems that contribute to progressive declines of physical function with advanced age, and lifestyle factors (e.g. chronic disease and inactivity) can dramatically accelerate these physiological reductions (Hunter et al., 2016). The pool of participants that are eligible to enroll in cross-sectional research studies therefore reduces with aging due to chronic diseases and death. For example, in the United States, the probability that a person will survive from birth to age 80 is only $57.8 \%$ (Arias \& Xu, 2018). Consequently, cross-sectional data from studies involving highly functioning older adult volunteers is often representative of a healthier and more select adult than their younger counterparts. Such 'super survivors' that are more 'elite' than the younger adults in the cross-sectional comparison likely, result in an underestimation of the effects of aging in the general population. For example, a 12-year longitudinal study of healthy, older and sedentary men demonstrated a $\sim 3 \mathrm{~N} \mathrm{~m}^{-1} \cdot$ year $^{-1}$ reduction in muscle strength (Frontera et al., 2000) whereas cross-sectional data estimate the annual decline in strength was only $\sim 1.5 \mathrm{~N} \mathrm{~m}^{-1}$. year $^{-1}$ (Frontera,
Hughes, Lutz, \& Evans, 1991). Despite these clear limitations in cross-sectional data for both sexes, examining elite world records may minimize the impact of 'super survivors' by examining elite athletes within each age cohort, young or old.

Another complicating factor is that even among the most elite older athletes, there is an overall reduction in the exercise training stimulus (i.e. intensity, duration and frequency) compared with younger athletes (Tanaka \& Seals, 2008), which may contribute to the increasing rate of decline in exercise performance with advanced age. In summary, the influences of:

- historical sampling bias for women;

- comparison of young adults to the elite 'super survivor' older adults;

- age-related reductions in training stimulus (training volume and intensity) may limit the cross-sectional data from being a pure model of human biological aging.

\subsection{Other factors}

In addition, there are other factors that may impact age-related declines in athletic performance but have substantial barriers to study scientifically:

- use of banned substances designed to enhance athletic performance i.e. "doping";

- regulated hormone levels.

For example, doping is primarily reported in younger male and female elite athletes, so if there is a lower incidence of doping in older athletes, the predicted age-related physiological decline would be exaggerated. Furthermore, intersex athletes, primarily androgenic women with physiologically elevated testosterone levels, would reduce the elite performance gap between men and women. Although there are substantial debates in science and sport about intersex athletes, elite intersex women such as Caster Semenya (a two-time Olympic champion in the women's $800 \mathrm{~m}$ ) who have been recently setting record performances in younger but not older age groups, could also exacerbate the predicted physiological decline with aging.

\section{Conclusion}

Although there are inherent limitations with using Masters athletic performance as proxy for human aging, datasets that encompass robust participation numbers across the lifespan may be a feasible model to estimate healthy human aging. Two limitations are the bias from the cross-sectional design of the studies data and the underrepresentation of women. There is nearly a universal decline in performance times that is greater among women than men across the lifespan. We estimate that Masters athletic performances, particularly marathon running, will be fundamentally biased until the oldest women have similar historical opportunity for competition and training as the men. Thus, to more accurately estimate healthy human aging in both men and women, we recommend that datasets fulfill at least the following two criteria: 
- have an adequately large dataset of both men and women;

- involve athletic events that enable similar opportunity for competition and training for men and women across the lifespan.

Under such circumstances, a comparison of the best athletic performances across age-groups (e.g. world records) may provide more accurate insight to the agerelated reductions in human physiology and function independent of activity.

Acknowledgements. We thank Dr. Vianney Rozand for helpful suggestions concerning the manuscript.

\section{Author contributions}

J.W.S. and S.K.H. drafted manuscript, edited and revised manuscript, and approved final version of manuscript; J.W.S. prepared figures.

\section{References}

Angus, S.D. (2019). A Statistical Timetable for the Sub-2-Hour Marathon. Med Sci Sports Exerc, 51(7), 1460-1466. Retrieved from https://www.ncbi.nlm.nih.gov/pubmed/ 30817713.

Arias, E., \& Xu, J. (2018). United States life tables. National Vital Statistics Reports, 67(7).

Belsky, D.W., Caspi, A., Houts, R., Cohen, H.J., Corcoran, D.L., Danese, A., Harrington, H., Israel, S., Levine, M.E., Schaefer, J.D., Sugden, K., Williams, B., Yashin, A.I., Poulton, R., \& Moffitt, T.E. (2015). Quantification of biological aging in young adults. Proc Natl Acad Sci U S A, 112(30), E4104E4110.

DiPietro, L. (2001). Physical activity in aging: changes in patterns and their relationship to health and function. $J$ Gerontol A Biol Sci Med Sci, 56(Spec No. 2), 13-22.

Donato, A.J., Tench, K., Glueck, D.H., Seals, D.R., Eskurza, I., \& Tanaka, H. (2003). Declines in physiological functional capacity with age: a longitudinal study in peak swimming performance. J Appl Physiol (1985), 94(2), 764-769.

Fitzgerald, M.D., Tanaka, H., Tran, Z.V., \& Seals, D.R. (1997). Age-related declines in maximal aerobic capacity in regularly exercising vs. sedentary women: a meta-analysis. $J$ Appl Physiol (1985), 83(1), 160-165.

Frontera, W.R., Hughes, V.A., Fielding, R.A., Fiatarone, M.A., Evans, W.J., \& Roubenoff, R. (2000). Aging of skeletal muscle: a 12-yr longitudinal study. J Appl Physiol (1985), 88 (4), 1321-1326.

Frontera, W.R., Hughes, V.A., Lutz, K.J., \& Evans, W.J. (1991). A cross-sectional study of muscle strength and mass in 45- to 78-yr-old men and women. J Appl Physiol (1985), 71(2), 644650.

Harridge, S.D., \& Lazarus, N.R. (2017). Physical activity, aging, and physiological function. Physiology (Bethesda), 32(2), 152-161.

Heath, G.W., Hagberg, J.M., Ehsani, A.A., \& Holloszy, J.O. (1981). A physiological comparison of young and older endurance athletes. J Appl Physiol Respir Environ Exerc Physiol, 51(3), 634-640.

Hepple, R.T. (2014). Mitochondrial involvement and impact in aging skeletal muscle. Front Aging Neurosci, 6, 211.
Hunter, S.K. (2016a). The relevance of sex differences in performance fatigability. Med Sci Sports Exerc, 48(11), 2247-2256.

Hunter, S.K. (2016b). Sex differences in fatigability of dynamic contractions. Exp Physiol, 101(2), 250-255.

Hunter, S.K., Joyner, M.J., \& Jones, A.M. (2015). The two-hour marathon: what's the equivalent for women? J Appl Physiol (1985), 118(10), 1321-1323.

Hunter, S.K., Pereira, H.M., \& Keenan, K.G. (2016). The aging neuromuscular system and motor performance. $J$ Appl Physiol (1985), 121(4), 982-995.

Hunter, S.K., \& Stevens, A.A. (2013). Sex differences in marathon running with advanced age: physiology or participation? Med Sci Sports Exerc, 45(1), 148-156.

Hunter, S.K., Stevens, A.A., Magennis, K., Skelton, K.W., \& Fauth, M. (2011). Is there a sex difference in the age of elite marathon runners? Med Sci Sports Exerc, 43(4), 656-664.

Joyner, M.J. (1993). Physiological limiting factors and distance running: influence of gender and age on record performances. Exerc Sport Sci Rev, 21, 103-133.

Joyner, M.J. (2017). Physiological limits to endurance exercise performance: influence of sex. J Physiol, 595(9), 2949-2954.

Joyner, M.J., \& Coyle, E.F. (2008). Endurance exercise performance: the physiology of champions. J Physiol, 586 (1), 35-44.

Kuh, D., Karunananthan, S., Bergman, H., \& Cooper, R. (2014). A life-course approach to healthy ageing: maintaining physical capability. Proc Nutr Soc, 73(2), 237-248.

Lara, J., Cooper, R., Nissan, J., Ginty, A.T., Khaw, K.T., Deary, I.J., Lord, J.M., Kuh, D., \& Mathers, J.C. (2015). A proposed panel of biomarkers of healthy ageing. BMC Med, 13, 222.

Lazarus, N.R., \& Harridge, S.D.R. (2017). Declining performance of master athletes: silhouettes of the trajectory of healthy human ageing? J Physiol, 595(9), 2941-2948.

Lazarus, N.R., Lord, J.M., \& Harridge, S.D.R. (2019). The relationships and interactions between age, exercise and physiological function. J Physiol, 597(5), 1299-1309.

Lepers, R., \& Maffiuletti, N.A. (2011). Age and gender interactions in ultraendurance performance: insight from the triathlon. Med Sci Sports Exerc, 43(1), 134-139.

Lepers, R., Sultana, F., Bernard, T., Hausswirth, C., \& Brisswalter, J. (2010). Age-related changes in triathlon performances. Int J Sports Med, 31(4), 251-256.

Myers, J., Prakash, M., Froelicher, V., Do, D., Partington, S., \& Atwood, J.E. (2002). Exercise capacity and mortality among men referred for exercise testing. $N$ Engl J Med, 346 (11), 793-801.

Nilwik, R., Snijders, T., Leenders, M., Groen, B.B., van Kranenburg, J., Verdijk, L.B., \& van Loon, L.J. (2013). The decline in skeletal muscle mass with aging is mainly attributed to a reduction in type II muscle fiber size. Exp Gerontol, 48(5), 492-498.

Pimentel, A.E., Gentile, C.L., Tanaka, H., Seals, D.R., \& Gates, P.E. (2003). Greater rate of decline in maximal aerobic capacity with age in endurance-trained than in sedentary men. J Appl Physiol (1985), 94(6), 2406-2413.

Power, G.A., Allen, M.D., Gilmore, K.J., Stashuk, D.W., Doherty, T.J., Hepple, R.T., Taivassalo, T., \& Rice, C.L. (2016). Motor unit number and transmission stability in octogenarian World Class Athletes: can age-related deficits be outrun? J Appl Physiol (1985), jap 00149 02016. DOI: 10.1152/japplphysiol.00149.2016.

Power, G.A., Minozzo, F.C., Spendiff, S., Filion, M.E., Konokhova, Y., Purves-Smith, M.F., Pion, C., AubertinLeheudre, M., Morais, J.A., Herzog, W., Hepple, R.T., Taivassalo, T., \& Rassier, D.E. (2016). Reduction in single 
muscle fiber rate of force development with aging is not attenuated in world class older masters athletes. Am J Physiol Cell Physiol, 310(4), C318-C327.

Prevention, C.f.D.C.a. (Producer). (2013). The state of aging and health in America.

Ransdell, L.B., Vener, J., \& Huberty, J. (2009). Masters athletes: an analysis of running, swimming and cycling performance by age and gender. J Exerc Sci Fitness, 7(2), S61-S73.

Senefeld, J., Joyner, M.J., Stevens, A., \& Hunter, S.K. (2016). Sex differences in elite swimming with advanced age are less than marathon running. Scand J Med Sci Sports, 26(1), $17-28$.

Senefeld, J., \& Sundberg, C.W. (2017). Predicting human ageing with Masters athletics: 'one size doesn't fit all'. J Physiol, 595 (22), 6813-6815.

Sundberg, C.W., Hunter, S.K., Trappe, S.W., Smith, C.S., \& Fitts, R.H. (2018). Effects of elevated $\mathrm{H}(+)$ and $\mathrm{Pi}$ on the contractile mechanics of skeletal muscle fibres from young and old men: implications for muscle fatigue in humans. $J$ Physiol, 596(17), 3993-4015.

Tanaka, H., \& Seals, D.R. (1997). Age and gender interactions in physiological functional capacity: insight from swimming performance. J Appl Physiol (1985), 82(3), 846-851.
Tanaka, H., \& Seals, D.R. (2003). Invited Review: Dynamic exercise performance in Masters athletes: insight into the effects of primary human aging on physiological functional capacity. J Appl Physiol (1985), 95(5), 2152-2162.

Tanaka, H., \& Seals, D.R. (2008). Endurance exercise performance in Masters athletes: age-associated changes and underlying physiological mechanisms. J Physiol, 586(1), 55-63.

Trappe, S., Hayes, E., Galpin, A., Kaminsky, L., Jemiolo, B., Fink, W., Trappe, S., Jansson, A., Gustafsson, T., Tesch, P. (2013). New records in aerobic power among octogenarian lifelong endurance athletes. J Appl Physiol (1985), 114(1), $3-10$.

Trappe, S.W., Costill, D.L., Vukovich, M.D., Jones, J., \& Melham, T. (1996). Aging among elite distance runners: a 22-year longitudinal study. J Appl Physiol (1985), 80(1), 285-290.

Vaupel, J.W. (2010). Biodemography of human ageing. Nature, 464(7288), 536-542.

Weiss, E.P., Spina, R.J., Holloszy, J.O., \& Ehsani, A.A. (2006). Gender differences in the decline in aerobic capacity and its physiological determinants during the later decades of life. $J$ Appl Physiol, 101(3), 938-944.

Cite this article as: Senefeld JW \& Hunter SK (2019) Are masters athletic performances predictive of human aging in men and women? Mov Sport Sci/Sci Mot, 104, 5-12 